\title{
Stress During ACLS Courses. Is it Important for Learning Skills?
}

\author{
Emilton Lima Júnior, José Knopfholz, Carla M. Menini \\ Curitiba, PR - Brazil
}

\begin{abstract}
Objective - To determine the influence of stress on teaching medical emergencies in an Advanced Cardiac Life Support (ACLS) course and to verify this influence on learning, and the efficiency of emergency care training.

Methods - Seventeen physicians signed up for an ACLS course. Their pulses were taken and blood pressure $(B P)$ verified on the first day, before the beginning of the course, and on the second day, during the theoretical and practical test (TPT). Variations in pulse rates and BP were compared with students' test grades. Then, students answered a questionnaire of variables $(Q V)$ about the amount of sleep they had during the course, the quantity of study material and the time spent studying for the course, and a stress scale graphic.
\end{abstract}

Results - Seven students had a pulse variation less than $10 \%$ between the 2 periods and 10 had a $10 \%$ or more variation. Grades on TPT were, respectively, $91.4 \pm 2.4$ and $87.3 \pm 5.2(p<0.05)$. Six students had a BP variation less than $20 \mathrm{mmHg}$, and in 11 it varied more than $21 \mathrm{mmHg}$. Grades on the TPT were $92.3 \pm 3.3$ and $86.2 \pm 8.1$, respectively $(p<0.05)$. The $Q V$ dates did not significantly influence grades.

Conclusion - Stress, as an isolated variable, had a negative influence on the learning process and on the efficiency of emergency training in this situation.

Keywords: stress, ACLS, cardiology, medical education

Pontifical Catholic University of Paraná - PUCPR, Brazil

Mailing address: Emilton Lima Júnior - Rue Gilles Magnée, 1/25 - 4430 - Ans -

Liège-Belgium - E-mail: emilton.lima@teledisnet.be - emiltonj@rla01.pucpr.br
In recent years, cardiology emergency courses have been developed for a greater number of emergency and nonemergency care physicians. We know that adult learning is different and different pedagogic techniques for learning are needed. In medical education, a new paradigm, Problem Based Learning (PBL), has been presented. It is a revolutionary pedagogic technique that stimulates learning based in real situations ${ }^{1}$, and Advanced Cardiology Life Support (ACLS) courses are an example of it. In ACLS courses from American Heart Association ${ }^{2}$ in particular, we have observed that course methodology encourages instructors to apply stress during student training to create a real emergency service atmosphere. Some ACLS instructors believe that stress during emergency situations must be managed by physicians. However, this technique has received criticisms from ACLS students, who say that it disturbs their performance, during the course.

Stress is important and positive in human life, and it is responsible for our capacity to adapt to new situations, good or bad ${ }^{3}$. Reaction to stress evokes complex neuroendocrine mechanisms, and stress can affect memory ${ }^{4}$ and learning ${ }^{5}$. Stress may also directly affect skills ${ }^{6}$, and in training courses it has been demonstrated that stress may affect students learning ${ }^{7}$ in different areas ${ }^{8}$ with different stressor agents ${ }^{9,10}$. In medical education where stress is part of the training, it may happen and we do not perceive it.

The aim of this study was to learn more about the effects of instructor-induced stress on student learning during ACLS training courses.

\section{Methods}

Seventeen physicians were studied who enrolled in an ACLS course. Students received the ACLS book to study 4 weeks before the course with an orientation letter, reinforcing the importance of prior reading of principal points in the book. The course was given on 2 weekend days. During the morning of the first day during the breakfast period before any pedagogic activity, the first blood pressure and heart rate measurements were taken. This time was conside- 
red the minimum stress level period. Students received a questionnaire that they were to complete and return at the end of second day, with these 5 questions: 1) How much sleep did you have the night before the course? 2) How much sleep did you have at night during the course? 3) How much did you read from the ACLS book? 4) How many hours do you work per day? 5) How many days, before the start of the course, did you start reading the ACLS book? With these data, we could identify others factors that may influence the ACLS assessment.

They also received a graphic stress scale for recording the perceived stress level-for each of 9 situations: 1) universal algorithm/basic life support; 2) external automatic defibrillator; 3) ventricular fibrillation and ventricular tachycardia without pulse; 4) stable and unstable tachycardia; 5) bradycardia and asystole; 6) pulseless electrical activity; 7) acute myocardial infarction, shock, acute lung edema; 8) special situations and; 9) megacode.

It is very difficult to determine the perceived stress level, to change subjective to objective information. We used a modified quality of life scale that consisted of a $10-\mathrm{cm}$ line (without values) and a lateral median starting point. Students had to trace a line starting at this point to the level of perceived stress, for each ACLS practical situation (fig. 1). With this method, we were able to determine more precisely the values for perceived stress.

During the ACLS theoretical evaluation, at the end of second day, students were given a practical evaluation, and at the end of this practical evaluation, before they returned to the theoretical evaluation, another blood pressure and heart rate measurement was taken, this moment being considered the period of maximum stress.

We compared perceived stress values, physical signs of stress (blood pressure and heart rate), grade on the ACLS theoretical evaluation, and the responses on the 5question questionnaire.

We separated the students into the following groups: 1) heart rate variation above and below $10 \%{ }^{11}$; 2 ) systolic blood pressure variation above and below $20 \mathrm{mmHg}^{12} ; 3$ )

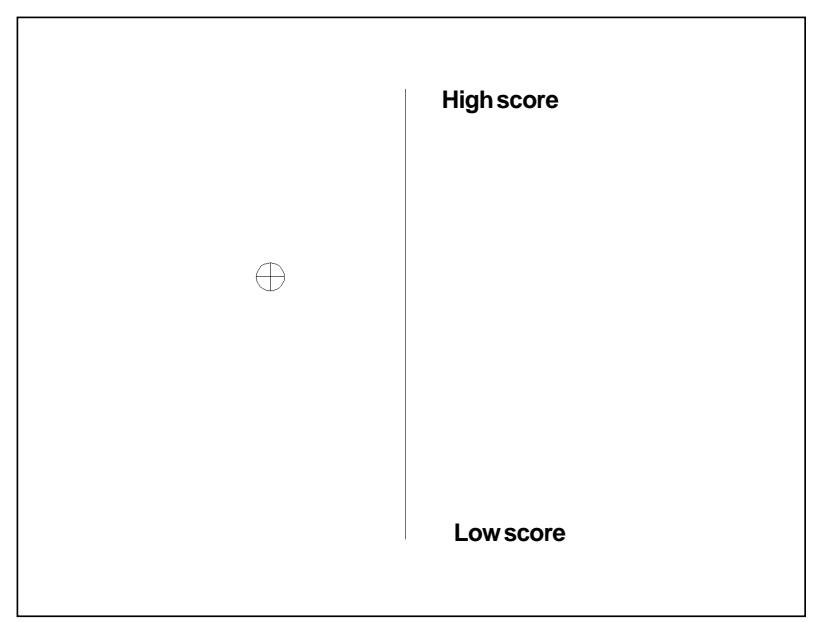

Fig. 1 - Graphic stress scale sleep duration above and below 70\%; 4) ACLS book reading above and below $30 \%$; 5) time of ACLS book reading above and below 2 weeks; 6 ) perceived stress scale above and below $50 \%$.

We performed the statistical analysis with the paired $t$ test with a 5\% significance level and made the linear regression statistical analysis comparing heart rate and systolic blood pressure, maximum and minimum stress time difference, and grade on the ACLS theoretical examination.

\section{Results}

The general characteristics of the population were mean age $42 \pm 12.6 ; 9$ males (52.9\%) and 8 females (47.1\%); 12 clinical physicians (70.6\%) and 5 surgeons (29.4\%).

Ten students had heart rate variations above $10 \%$ and a mean grade on the ACLS theoretical examination of $87.3 \pm 5.2$ (fig. 2). Seven students had heart rate variations below $10 \%$ and examination scores of $91.4 \pm 2.4(p<0.05)$.

Eleven students had systolic blood pressure variations above $20 \mathrm{mmHg}$ and a mean grade on the ACLS theoretical examination of $86.2 \pm 8.1$ (fig. 3). Six students had systolic blood pressure variations below $20 \mathrm{mmHg}$ and theoretical examination scores of $92.3 \pm 3.3(p<0.05)$.

Six students received less than $70 \%$ of their regular sleep time and their mean grade on the ACLS theoretical examination was $88.6 \pm 7.7$, and 11 students who received less than $70 \%$ of their regular sleep time had scores of $87.8 \pm 8.7(\mathrm{p}=0.96)$.

Seven students had read more than $30 \%$, and their mean grade on the ACLS theoretical examination was $87.5 \pm 9.6$, and 10 students that read less than $30 \%$ had scores of $88.8 \pm 7(\mathrm{p}=0.99)$.

Eight students studied more than 2 weeks. Their mean grade on the ACLS theoretical examination was 87.9 4 . Nine students that had studied for less than 2 weeks had a mean grade of $88.4 \pm 8.3(\mathrm{p}=0.66)$.

In the 9 ACLS practical skill situations, 91 scores were $50 \%$ higher for perceived stress level and 62 were below

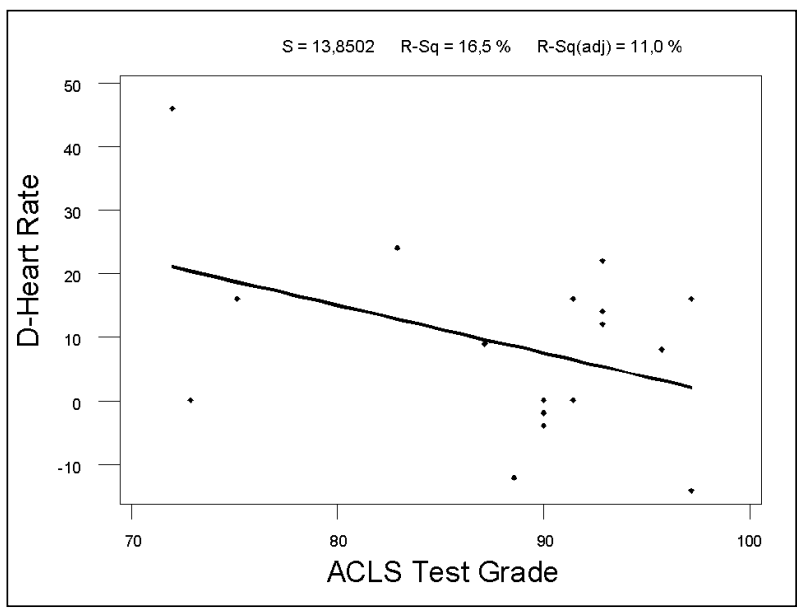

Fig. 2 - Linear regression - Heart rate difference: Maximum/minimum stress time. 


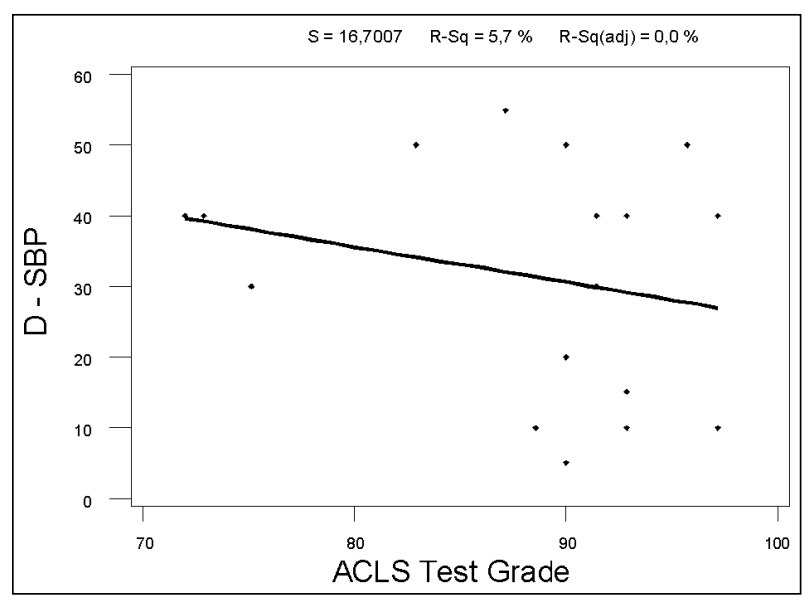

Fig. 3 - Linear regression - Systolic blood pressure difference: Maximum/minimum stress time.

$50 \%$. The mean grades on the ACLS theoretical examination were $87.5 \pm 1.3$ for the above $50 \%$ group and $90.1 \pm 2.3$ for the below $50 \%$ group $(\mathrm{p}<0.05)$.

\section{Discussion}

The objective of this study was to evaluate the impact of stress on learning during an ACLS course. We studied physiological variables (heart rate and systolic blood pressure), environment variables (study time and quantity), and behavioral variables (sleep time and perceived stress), and these variables were compared with student performance in the ACLS course.

In recent decades, a great number of studies have been performed about pathophysiological stress mechanisms ${ }^{13-15}$, and we know the neuroendocrine system plays an important role in this pathophysiology ${ }^{16}$, and the activation of the sympathetic nervous system is important in the acute physiological response in stress situations ${ }^{17}$. Increased heart rate ${ }^{18}$ and blood pressure ${ }^{19}$ are important parts of this homeostatic reaction too.

In the physiological variables, we found a significant correlation between a higher heart rate and a lower grade on the ACLS theoretical examination. In situations of stress, an increase occurs in the basal heart rate ${ }^{18}$. We can conclude that stress influences student performances on the ACLS theoretical examination, in our observation. And when we observed systolic blood pressure, we had a significant correlation between higher levels of systolic blood pressure and lower grades on the ACLS theoretical examination. Looking at the same pathophysiological mechanisms ${ }^{19}$ of heart rate, we can conclude also that stress may play a role in student performance on the ACLS theoretical examination.

In the environmental variables, curiously, we did not find a significant correlation between the study loads (time and/or quantity) and student performance on the ACLS theoretical examination. These variables did not have an influence or were a cause of bias in this study. Probably, because, during the ACLS course, students received the necessary theoretical information in the theory classes, for their better performances.

In the behavioral variables, no significant difference occurred between sleep time and performance on the ACLS theoretical evaluation. However, we found significant differences between the perceived stress scale and student performance. This means that the stress perceived by students, in this ACLS course, was a determinant in their performance.

The perceived stress scale, it was shown in this study, is a good tool for perceived stress research, and it may be better than a questionnaire ${ }^{20}$, because this scale changes qualitative into quantitative data. To prove this, more research is needed that uses this scale against different kinds of perceived stress questionnaires.

Student performance in the practical assessments were not considered for analysis, because with this sample binary data (ie, past or not past) are inconsistent, and we could have biased data.

With these data, discussion about stress and learning during ACLS courses can begin. Perhaps we need to think about remodeling the pedagogic techniques of ACLS courses, and other courses that use these kinds of stress techniques, to improve student performance. However, we must not forget that the stress is a variable present in emergency care services, and physicians must know how to manage stress factor to achieve better performance and emergency patient safety.

We would like to suggest that information and skills training about stress management ${ }^{21}$ should be included in ACLS courses, and other emergency care courses, and perhaps we could, in a better way, reach emergency course objectives. Further studies should be undertaken to understand more about the effect of stress, training skills, and learning in medicine.

\section{References}

1. Albanese MA. Problem-based learning: A review of literature on its outcomes and implementation issues. Acad Med 1993; 68: 52-81.

2. American Heart Association. Advanced Cardiology Life Support Course. 2001. Available from: URL: http://www.cpr-ecc.org/T_courses/Tcor.SAVC. hmt\# anchor10.

3. Lipp MEN. Estresse: Conceitos básicos. In:. Pesquisas sobre estresse no
Brasil: Saúde, ocupações e grupos de risco. Campinas, São Paulo: Papirus; 1996: 17-31.

4. Newcomer JW, Selke G, Melson AK, Hershey T Craft S, Alderson A. Dose and time-dependent cortisol-induced decreases in human declarative memory (abstract). XXIX Annual Meeting of International Society of Psychoneuroendocrinology, Trier, Germany 1998. 
5. Ohl F, Fuchs E. Chronic estresse modulates cognitive performance [abstract] XXIX Annual meeting of International Society of Psychoneuroendocrinology, Trier, Germany 1998.

6. Wilkinson RT. Performance under estresse. Proc R Soc Med 1975; 68: 425-7.

7. Meister EK, Bruck I, Antoniuk SA, et al. Learning disabilities: analysis of 69 children. Arq Neuropsiquiatr 2001; 59(2-B): 338-41.

8. Stout RJ, Salas E, Kraiger K. The role of trainee knowledge structures in aviation team environments. Int J Aviat Psychol 1997;7: 235-50.

9. Hancock PA, Vasmatzidis I. Human occupational and performance limits under estresse: the thermal environment as a prototypical example. Ergonomics 1998; 41: 1169-91.

10. Haines MM, Stansfeld SA, Job RF, Berglund B, Head J. A follow-up study of effects of chronic aircraft noise exposure on child estresse responses and cognition. Int J Epidemiol 2001; 30: 839-45.

11. Weil LJ, Loran. Life Estresse and bodily changes: a formulation. In: . Estresse and Body Diseases Baltimore: New York, New York: Williams and Wilkins, 1996: 1437-52.

12. Ayres AMM. Estresse, afetividade e reatividade cardiovascular em adultos hipertensos e normotensos [dissertation]. Pontifícia Universidade Católica de Campinas, 1994.
13. Brunner E. Estresse and the biology of inequality. Br Med J 1997; 314: 1472-6.

14. Zeitlin LR. Organization downsizing and estresse-related illness. Int J Estresse Manag 1995; 2: 207-20.

15. Kobasa SC. Estresseful life events, personality and health: an inquiry into hardiness. J Psychol 1979; 37: 1-11.

16. Pacák K, Palkovits M. Estresseor specificity of central neuroendocrine response: implications for estresse-related disorders. Endocr Rev 2001; 22: 502-48.

17. Szafarczyk A, Ixart G, Gaillet S, et al. Estresse: Données neurophysiologiques. L'Encéphale 1993; 19: 137-42.

18. Palatini P. Elevated heart rate as a predictor of increase cardiovascular morbidity. J Hypertens 1999; 17(suppl. 3): S3-S10

19. Esler M, Kaye D. Sympathetic nervous activation in essential hypertension, cardiac failure and psychosomatic heart disease. J Cardiovasc Pharmacol 2000; 35(suppl. 4): S1-S7.

20. Hodgkins BJ, Manring E, Meyers MA. Demographic, social and estresse correlates of hypertension among urban poor. Fam Prac 1990; 7: 261-6.

21. Fiedler FE, Potter EH 3rd, Zais MM, Knowlton WA Jr. Organizational estresse and the use and misuse of managerial intelligence and experience. J Appl Psychol 1979; 64: 635-47. 